\title{
Investment Risk Management and a Case Study
}

\author{
Linhui Sheng \\ School of Business Administration, China University of Petroleum-Beijing, 102249, China; \\ 931990300@qq.com
}

Keywords: Risk Management, Case Study, Review

\begin{abstract}
Risk management refers to the management process that minimizes the risk of a project or an enterprise in a risky environment. After many crises, nowadays, business crises have never stopped. Based on the concept and purpose of risk management, this paper gives an overview of the development of investment risk management tools, and takes the RC electro thermic film product from RC Warm Era Limited Liability Company as an example, analyzing its internal and external risks. Correctly understanding of risk management is conducive to maintaining the stability of production and operation, meanwhile improving the economic efficiency of enterprises.
\end{abstract}

\section{Introduction}

Investment is a profound knowledge, and it can be also said to be an art. The boom of capital market, the fluctuations of capital market prices of various commodities, the uncertainty of the trend, affect the emotions of investors and the lives of people. Financial investment is part of the lives of people. Whether individuals, businesses, local governments or countries are all concerned about the investment and investment risks. In a period of economic growth, investment profits are attractive, and in the moment of attaining profits investors often overlook risk management. From the track of the stock market history, we can see that there is a short market about 3 years with a lot of decline in average every 10 years [1].Recall several financial catastrophes in the history, such as the Great Depression in 1923. The collapse of many financial institutions and enterprises brought about the high unemployment rate, endangering the lives of individual families and social security. In 2000, the dot-com bubble bursting resulted in a three-year short stock market. Even many conservative pension accounts shrunk dramatically so that many retired elderly people had to return to the workplace. In 2008 financial tsunami subprime mortgage crisis swept the global financial markets, which led to many companies shutting down business. The largest companies of many areas globally for decades, such as Citigroup, AIG, and General Motors were on the verge of bankruptcy. The top five investment banks in the United States, only Goldman Sachs vented CDS and other financial derivatives hedge properly, avoiding the crisis at last. Iceland encountered national bankruptcy and reorganization, the Greek debt crisis in 2011 opened the first shot of the debt crisis in Europe. The euro zone got caught into a debt crisis in Europe. The unemployment rate continued to improve, the economy was in recession, investors scarred, the lives of people were hard and the society lost its order, the affected individuals and families were difficult to estimate.

After many crises, nowadays, many corporate crises have never stopped, and the risks do not seem to occur only in the short period. For example, the personal assets of Brazil's richest man in 2012 was 34.5 billion US dollars, due to underestimate the risk of improper investment, to September 2013 just over a year, the company market value of $96 \%$ of was lost and the debt is worth 11 times market value. Therefore, if the risk management is inappropriate, wealth is like a cloud.

Based on the concept and purpose of risk management, this study summarizes the development of investment risk management tools. And it takes the $\mathrm{RC}$ electrothermic film product from RC Warm Era Limited Liability Company for example, analyzing its internal and external risks. Correct understanding of risk management is conducive to maintaining the stability of production and operation and improving the economic efficiency of enterprises. 


\section{The Concept and Purpose of Risk Management}

What is risk? Risk is the uncertainty of future earnings. F. Knight (1921) refers to the uncertainty of what results will occur, and it means that the probability of occurrence of the event occurred from the historical data analysis. There are still uncertain future results [2]. The core of investment management lies in asset pricing and asset risk measurement, while asset pricing focuses on asset uncertainty risk measurement, which represents that controlling uncertainty profit and risk is the important work of investment management.

Risk management refers to the management process that minimizes the risk of a project or an enterprise in a risky environment. Investment is risky. If the risk is controlled, but no profit, that is not the purpose of risk management actually. The purpose of risk management can be illustrated by capital asset pricing model (CAMP model) Sharp (1963) proposed [23]. The CAMP model formula is:

$R=\alpha+\beta\left(R_{m}-R_{f}\right)+\varepsilon$

The simplified formula is:

$R_{a}=\alpha+\beta M_{r}+\varepsilon$

Among them,

$R_{a}$ : Actual yield or asset value

$\alpha$ : The profit or original asset value

$\beta$ : Investment risk management capacity coefficient

$M_{r}$ : Excess returns of exceeding the market

The purpose of risk management is divided into three areas: the first one is to stick to $\alpha$, which can be defined as an existing profit. For example, when a company receives a list, its offer is based on cost plus profit. The purpose of risk control is to stick to $\alpha$. It can use the hedge strategy of derivatives to retain the original profit or protect the price of existing assets so that it is not affected by the future price fluctuations. The second is to make the market excess profit $M_{\mathrm{r}}$ at least greater than or equal to zero or maintain a persistent positive value. The third is to maintain the $\beta \geq 0$ and make $\beta M_{\mathrm{r}} \geq 0$. Business operators should have a firm management strategy that sticks to the $\alpha$ strategy, and use the financial derivatives to make $\beta M_{\mathrm{r}}$ zero, and earn available production profits. They should not have speculative mentality in the future uncertainty volatility risk, and keep sustained and stable development. For individual investors, the value of $\alpha$ is the dividend or profitable portion of a company. Such as retirement capital should be used to obtain dividend profits. It can make good use of financial derivatives to make $\beta M_{\mathrm{r}}$ zero so as to be free from market volatility impact profit. For financial investors, they can use financial derivatives to make the value of $\beta M_{\mathrm{r}}$ in the portfolio not negative.

In the asset pricing theory, the larger the value of $\beta$ means the stock picking ability the better, the increase of the rate is greater than the average market amplitude, and the larger the $R_{m}-R_{f}$. Market volatility is greater than the risk-free profits. The general investors tend to focus on $\beta$ and $R_{m}$. In the stock market bulls, it seems to be on the strategy. However, the problem is that if the time variable and financial investment financing leveraged multiples operation are added, and derivatives have a small broad nature, the greater value of $\beta$ for the investment target, the loss may be difficult to compensate when the bulls are reversed.

In fact, in the traditional stocks and bonds portfolio, these theoretical tools and the historical data are used to predict the uncertain future. Not only the $\beta$ index cannot withstand the long-term test, but also the traditional financial instruments and financial risk management tools are often effective for a while. The core of the problem may be lack a core element in the traditional stock, bonds, commodities, and gold energy portfolio. This core element is not so much a lack of financial derivatives as a lack of risk control mechanisms or behavior. We may invest in decentralized but do 
not spread the risk, on the contrary the risk may be increased. Increasing financial derivatives or licensing can significantly improve and reduce risk, but not all financial derivatives can reduce risk. Because the investment is scattered in different baskets. If the nature is similar, it is only the same nature of the basket. In 2008, the weighted average of all financial derivatives hedge funds at the Center for Information Securities and Derivatives Markets (CISDM) also fell as much as stocks, with an average of $\$ 21.27 \%$ in all hedge funds. It seems that the risk of hedge funds is not small, and cannot avoid the risk just like the stock. The importance of risk control is unquestionable, but how can the risk control mechanism be able to withstand the long-term test in the financial market and make the risk control play its value and significance.

\section{Development of Investment Risk Management Tools}

Risk management tool measurement analysis is to establish a variety of analysis models, analyzing the uncertain factors that affect the fluctuation of asset price. So that it can improve the risk in the controllable range, and control the possible risk of loss. With the rapid change of environment and the complexity of the degree of market risk affects variables, the variables required by the risk measurement and analysis model also change and evolve.

Before the VaR (Value at Risk) risk measurement tool appeared, there was gap analysis which analyzes the impact of interest rates on the income of assets or liabilities. Duration analysis: Analyze the duration of a bond. Duration is the weighted average of the various periods of bond cash flow. Scenario analysis: Assume the profit and loss analysis under different scenarios. And Portfolio theory: Choose the investment target according to the expected return and the standard deviation.

VaR risk measurement tool aggregates and calculates all the risks of a portfolio of financial investments as a single value to measure the maximum amount of loss that a portfolio may generate for a given period of time at a given probability of trust level. That is, in the asset specific time range, under a certain probability setting conditions, using its mean and standard deviation to calculate the maximum possible loss. So you can make a consistent measure of risk for different categories of assets. Assuming the market value of a portfolio is $\mathrm{V}$, the return volatility of the portfolio is $\sigma$, the trust level is $\alpha$, the period holding the portfolio is $\mathrm{t}$, and the $\mathrm{VaR}$ at the normal distribution mean is assumed to be below.

$\operatorname{VaR}=-q_{p}$

Among the $q_{p}=Z_{\alpha} \times \sigma \times V \times \sqrt{t}, Z_{\alpha}$ is the level of confidence.

According to the extreme value theory, under extreme conditions, such as Gnedenko (1943) proposed Gumbel, Frechet and Weibull three extreme distribution. When the assets belong to different extreme values, the $\mathrm{VaR}$ will be different under the extreme value conditions. Therefore, the primary task in the extreme value analysis is to determine what the extreme value distribution of the asset [4]. In recent years, extreme value theory has been widely used in extreme climate, medical statistics, labor market, education population and other different studies. Such as Moshe Buchinsky in 1994 analyzed the US labor market wages, female wages and other structural changes with the quantile regression [5].

\section{Risk Management Case Study}

$\mathrm{RC}$ warm era limited liability company is to provide all kinds of $\mathrm{RC}$ ( $\mathrm{R}$ refers to the resistance, $\mathrm{C}$ refers to the capacitor) electrothermic products for the main business of the company, that is, $\mathrm{RC}$ electric film coated on the surface to be heated to make all kinds of heating Equipment products. It is mainly for the market heating products, building heating, industrial heating and other types of civil and special heating.

$\mathrm{RC}$ electrothermic film products in the field of production and life has a unique development prospects, but when entering the market, inevitably with the risk. We from the internal risk and external risk of the two aspects of the risk of the product on a detailed analysis. 


\subsection{Internal Risk.}

As the RC electrothermic film is a production equipment company, it needs the support of core RC electrothermic technology. And in the initial stage, the company will consider a certain risk in the capital when it needs financial support. In addition, the difference between the actual capacity of the operator and the expected difference should take into account the risk of management, the risk from the internal competitiveness of the industry, whether the production of the product in the production of the country and so on. From the technical risk, financial risk, industrial risk, production risk, management risks and other aspects of specific analysis. The main advantages in technology and industry, unique patented technology, $98.8 \%$ of the thermal conversion rate is already reached the highest level in the world. In addition, with the core technology support, the production of products can be diversified and have less competitive pressure.

\subsection{External Risk.}

From the external risk point of view, whether from the policy risk or environmental risk considerations, RC electro thermic film products have a great advantage. It is pollution-free throughout the entire production and the use of links, in full compliance with international environmental standards, which belongs to the scope of policy encouragement and support.

\section{Conclusion}

This paper expounds the concept and purpose of risk management, and gives an overview of the development of investment risk management tools. Finally, it analyzes the internal and external risks of RC electro thermic film products with RC warm day's limited liability Company.

There are many types of risk, and each risk category has a lot of factors, so risk management is a fairly complex system engineering. However, how to correctly identify the basic core of risk is the same, it is not clear how much risk is the greatest risk. Correctly assessing risk and assessing performance requires a number of risk identification theory tools, and these theoretical tools have their limits of use. So the use of these tools without a clear view will inevitably lead to valuation errors, leading to investment decisions. It is necessary to analyze the risk characteristics of holding assets in order to use the correct valuation method.

\section{References}

[1]. Ding, Z., Granger, C. W., \& Engle, R. F. A long memory property of stock market returns and a new model. Journal of empirical finance. 1(1) (1993), p.83-106.

[2]. Knight, F. H. Risk, uncertainty and profit. Hart, Schaffner and Marx. New York (1921), p.22.

[3]. Sharp, W. F. The Theory of Capital Asset Pricing. Management Sicenci, 1 (1963), p.137-149.

[4]. Gnedenko, B. Sur la distribution limite du terme maximum d'une serie aleatoire. Annals of mathematics, (1943), p. 423-453.

[5]. Buchinsky, M. Changes in the US wage structure 1963-1987: Application of quantile regression. Econometrica: Journal of the Econometric Society, (1994), p. 405-458. 